\title{
Comentario
}

\section{La información en las Comunidades Indígenas \\ ¿recurso minimizado?}

$\mathrm{E}$ de todos conocido que los grupos indígenas a través del tiempo han sufrido de altibajos en cuanto al modo de ser percibidos y tomados en cuenta por la sociedad que los rodea, lo que depende de la ubicación geográfica, la época, los sucesos históricos, el clima, los hechos políticos y económicos, entre otros.

Esta situación ha implicado que las diversas comunidades indígenas del país hayan tenido un desarrollo heterogéneo en relación a su cultura en todos los aspectos, dependiendo del acercamiento e interacción con otros grupos y de su propia actitud ante los diversos aspectos que conlleva el proceso de actualización y modernización de las sociedades.

Hablando en particular de las necesidades informativas y los recursos informativos, a través de los cuales satisfacen sus requerimientos, una gran parte de las comunidades han recurrido normalmente a sus propias fuentes, que son los ancianos y sabios que en algunos casos son integrantes de los Consejos que organizan y norman al interior el devenir de sus sociedades.

En otros casos los ancianos y sabios se aíslan de la comunidad pero aceptan que los individuos se acerquen a ellos para obtener respuestas a sus interrogantes. Aunque viven aislados, dichos personajes tienen un conocimiento profundo de la comunidad, lo que les da una basta experiencia en relación a varios aspectos que circundan la vida en común.

Existen comunidades en el país que han dado un gran salto en cuestión de información, debido a la práctica común de emigrar (ya sea por necesidad o por interés de conocer otras partes del mundo) que han tenido durante décadas, este hecho 
en particular ha ocasionado que obtengan amplios conocimientos sobre diversos aspectos tales como: variadas técnicas agrícolas y ganaderas, alimentación de animales, explotación de huertas y parcelas, floricultura, elaboración de productos agrícolas, ganaderos, textiles y artesanales, transportación de mercancías y tasación y mercadeo en la región, el país y la exportación al extranjero, protección del medio ambiente, desarrollos ecoturísticos, promoción y difusión de la medicina natural, entre otros.

Para lo anterior, los integrantes de las comunidades que han salido de sus lugares de origen y se han establecido en diversas partes del país, sobretodo en diversas localidades de Estados Unidos, en colaboración con algunas organizaciones no gubernamentales $(\mathrm{ONG})$ han creado redes de comunicación a través de Internet, construyendo páginas web y utilizando portales y programas como Viber y Skype o las redes sociales Facebook y Twitter.

Estas redes de comunicación han colaborado en el uso de diversas herramientas informativas que, a la vez que brindan información relevante para las comunidades, han generado conocimientos más amplios sobre diversos aspectos que influyen en la vida y las costumbres de los individuos originarios. Han servido también para fortalecer los lazos entre dichos individuos y aquellos que por una u otra razón han tenido que emigrar.

Las necesidades de información se han expandido a temas que anteriormente no habían sido relevantes para las comunidades, puesto que no concebían la emigración como un problema de existencia de la comunidad. En la actualidad, temas tales como derechos humanos, políticas públicas para inmigrantes, rescate de la cultura, moda, música, radio y televisión, son sólo algunos ejemplos de la proliferación de información que se ha extendido entre y para los integrantes de las comunidades.

El apoyo para la introducción de tecnologías de información y comunicación en y para las comunidades indígenas lo han tomado las ONG, dando capacitación para el uso de dichas tecnologías, elaboración e incorporación de páginas Web y acceso y consulta a diversos recursos de Internet, consiguiendo recursos económicos y materiales para la incorporación de equipos y medios electrónicos.

Entre otras ONG que resaltan por su trabajo y que han tomado la iniciativa para apoyar a las comunidades indígenas en 
este proceso, refiere Carmen Gómez Mont en el documento Los usos sociales de internet en comunidades indígenas mexicanas, se encuentran: "Ojo de Agua Comunicación" en el estado de Oaxaca, "La Neta" en la Ciudad de México y varios estados y "Redes Indígenas" en la Ciudad de México.

En contraste con las acciones emprendidas y mencionadas anteriormente, el gobierno ha carecido de políticas públicas permanentes que inserten a las comunidades indígenas en el medio tecnológico; ha sido incapaz de desarrollar proyectos que de manera paulatina pero constante introduzcan los recursos necesarios de cómputo a todas las comunidades (respetando su elección de integrarse a los medios electrónicos o no) para acceder a diferentes medios de comunicación, de información y elevar su conocimiento del mundo que les rodea.

Por otra parte, los bibliotecólogos también deben responder a los retos que implica la inserción de tecnologías de comunicación e información en las comunidades indígenas, es preciso que se incorporen proyectos colaborativos con entidades gubernamentales como la Secretaría de Comunicaciones y Transportes (SCT), la Comisión Nacional para el Desarrollo de los Pueblos Indígenas (CDI), la Dirección de Educación Indígena de la Secretaría de Educación Pública (SEP), el Instituto Nacional de Lenguas Indígenas (INALI), el Consejo Nacional de Fomento Educativo (CONAFE) y ONG, entre otras, y que los proyectos en cuestión verdaderamente resulten en beneficio de las comunidades indígenas y que no sirvan nada más para hacer difusión y promoción de las etnias del país.

El proceso de integración de tecnologías de información supone una serie de retos que deberán superarse; entre otros, se consideran los siguientes: vencer la apatía de los gobiernos federales, estatales y municipales para generar la infraestructura que se requiere en cada comunidad indígena para el establecimiento de Internet; priorizar la generación de paquetes de programas en las diversas lenguas para mayor interacción con y entre los integrantes de las diferentes comunidades; establecer unidades de información exprofeso para contener los servicios de información y comunicación requeridos por las comunidades; planear y aplicar un programa nacional de capacitación en el uso y manejo de los recursos tecnológicos y de información, acordes con los requerimientos informativos de las comunidades indígenas $\mathrm{y}$, a 
la par, organizar un programa nacional de inducción e incorporación a los servicios tecnológicos y de información, con el fin de contrarrestar la negación de las comunidades al uso de las nuevas tecnologías, entre otros.

A lo largo de esta exposición se percibe la importancia que tienen las tecnologías de la información y la comunicación y su uso adecuado por parte de las comunidades indígenas, por lo que no podemos ni remotamente dejar que las diversas entidades gubernamentales, ni los grandes consorcios ni las grandes masas poblacionales de nuestro país, minimicen el valor que para el desarrollo de los pueblos indígenas tendrían la información y la tecnología en la conservación de su cultura, así como la trascendencia de la obtención de nuevos conocimientos, consolidando una sociedad más fuerte y más justa a partir del apoyo a uno de sus estratos más desprotegidos: los grupos étnicos.

César Augusto Ramírez Velázquez 